\title{
As Debilidades Estruturais das Organizações: 0 Exemplo Ibérico
}

\author{
Arnaldo Coelho \\ Filipe Coelho
}

\section{RESUMO}

A partir dos resultados de um inquérito realizado junto de 187 empresas portuguesas e catalãs, pretendeu-se estudar a possibilidade de existir um déficit de estruturação entre estas empresas, susceptível de limitar a sua produtividade e a sua competitividade. As características específicas deste tecido empresarial, onde prevalecem empresas de pequena dimensão, com uma gestão familiar autodidacta, podem criar um quadro inibidor do desenvolvimento de uma vontade organizadora e que mantém muitas destas empresas amarradas a um estado pré-organizacional. Quando seria de esperar que estas empresas, que reconhecem estar a enfrentar um ambiente mais complexo, mais variável e mais hostil, estivessem a aligeirar e a flexibilizar as suas estruturas organizativas, assistese ao reforço generalizado destas, que parece coincidir com o reconhecimento desta necessidade. A confirmar-se este déficit, a sua resolução poderá ser um factor incontornável para reconduzir estas empresas na senda da competitividade.

Palavras-chaves: estrutura organizacional; ambiente.

\begin{abstract}
Based on a sample of 187 Portuguese and Spanish companies, we investigated the possible existence of a structural deficit, which may act as a barrier to these companies' productivity and competitiveness. The prevalence of small and medium-sized companies, characterised by a familiar management that is autodidact, might create barriers to an organising will and is keeping many companies tied to a pre-organizational state. In the context of an environment that is becoming increasingly complex, volatile and hostile, it could be expected that these companies would be adopting more flat and flexible organizational structures. Contrary to expectations, the results show that these companies have been reinforcing their organizational structure. If this structural gap exists, then its elimination will be essential to drive these companies into the competitive route.
\end{abstract}

Key words: organizational structure; environment. 


\section{INTRODUÇÃO}

A estrutura ideal ou o nível ideal de estruturação para uma empresa são temas cuja abordagem reveste alguma complexidade e cuja relevância é perfeitamente discutível. A estrutura organizacional apresenta um carácter transitório, volátil, à medida da volatilidade do ambiente em que a empresa está inserida. Nestes termos, falar de adaptabilidade das estruturas organizativas será, porventura, um tema mais actual e mais pertinente.

Todavia, se estudar a estrutura ideal poderá parecer hoje despiciendo, o estudo dos níveis de estruturação das organizações poderá apresentar alguma pertinência, não porque exista alguma escala ou medida de referência mas, sobretudo, pela suspeita que prevalece de que as empresas ibéricas, com destaque para as portuguesas, podem padecer de uma falta de estruturação que limita a sua produtividade. Ora, no nível da empresa, a produtividade condiciona a sua competitividade, do mesmo modo que no nível da economia nacional põe em causa as possibilidades de crescimento, sobretudo numa situação de pleno emprego, como a que se vive actualmente.

A partir dos resultados de um inquérito a 187 empresas portuguesas e espanholas, da região da Catalunha, foi possível extrair um conjunto de dados que apontam, precisamente, no sentido da prevalência de uma situação de subestruturação, de carácter endémico, que é mais visível nas empresas portuguesas. A dimensão destas empresas, associada a uma gestão de natureza familiar e autodidacta, parece ter um papel decisivo nesta situação, inibindo o seu desenvolvimento estrutural.

Este tema ganha uma particular actualidade se se tiver em conta que a generalidade destas empresas pôde concretizar um conjunto de investimentos impar nos seus historiais, com o apoio das comunidades europeias, sem que os níveis de competitividade alcançados fossem significativos. Em paralelo, a instantaneização do conhecimento relativo a mercados, tecnologias e matériasprimas, entre outros, faz com que a justificação para esta situação não passe por estes factores. Analogamente, os trabalhadores portugueses, espalhados um pouco por todo o mundo, vêm dando excelentes provas da sua produtividade. Em consequência, os problemas de produtividade e de competitividade terão que ter outras justificações, às quais a organização do trabalho e a estruturação das empresas não poderão ser alheias. 
Assim, sem abandonar o quadro conceptual dos pontos de vista contingentes, que pretende estudar a estrutura que melhor se adequa a cada contexto (Burns e Stalker,1961; Mintzberg, 1979; Fuente Sabaté, 1994; Donaldson, 1999; Coelho, 2000), o objectivo deste trabalho é o de contribuir para a discussão do problema da estruturação das empresas, assim como dos factores que, em cada situação, cultura ou país, mais contribuem para o seu estado estrutural.

\section{A Literatura}

A busca da estrutura ideal, enquadrada no âmbito de uma universalidade dos princípios de boa gestão, não está ainda fora dos horizontes da nossa memória. Há pouco mais de 60 anos, Urwick (1937) resumia, assim, os pontos de vista da teoria das organizações:

"o tema geral é que existem princípios aos quais chegamos por dedução, a partir do estudo das experiências humanas de qualquer natureza. Estes princípios podem ser estudados como questões técnicas, independentes dos objectivos da empresa, do pessoal que a compõe, ou de qualquer teoria constitucional, política ou social, sobre a qual esteja fundada".

A ruptura do paradigma clássico ou tradicional, deu um fim natural às veleidades universalistas que vinham prevalecendo. Apesar de ter tido o mérito de dar resposta a problemas básicos de organização e um tratamento sistemático e exaustivo ao processo administrativo, não teve a visão que lhe permitisse sair dos limites internos da organização, sucumbindo à erosão dos tempos e das conjunturas.

Assim, de um extremo universalismo, chegou-se a um extremo relativismo, em que a estruturação das empresas dependia da conjuntura em que se inseria: a eficácia da organização depende da adequação entre a sua estrutura e o contexto em que opera (Mintzberg, 1979; Donaldson; 1999). O comportamento, supostamente mimético, da estrutura em face dos factores de contexto, deu à natureza transitória das estruturas um carácter ainda mais volátil. E, assim, os factores de contingência multiplicaram-se: Woodward (1965) preocupou-se com a tecnologia; Pugh (1969) deu prioridade ao tamanho da empresa; Chandler (1962) avançou os efeitos da estratégia na estrutura organizacional; Burns e Stalker (1961), Fuente Sabaté (1994) e Coelho (2000) centraram-se nos efeitos do ambiente.

Não se podendo falar de uma estrutura ideal ou de um nível de estruturação ideal, nem todas as veleidades universalistas ficaram perdidas. Assim, na ausência de uma estrutura ideal, começou-se a trabalhar na procura da estrutura que melhor 
se ajustasse a cada contexto. Miles e Snow (1978) e Mintzberg (1979) não resistiram à tentação dos tipos ideais e alguns estudos apresentaram mesmo a efectividade organizacional em função da distância entre os parâmetros estruturais de cada empresa e o respectivo tipo ideal (Doty, Glick e Huber, 1993). A teoria das organizações passou pois a viver num limbo, entre o limiar do relativismo e os limites do universalismo. Donaldson (1996), no sentido de evitar esta armadilha, resume assim os pontos de vista contingentes:

. É uma teoria geral porque a partir de estudos empíricos mostra a existência de uma relação convergente entre a generalidade dos factores de contexto e os parâmetros estruturais.

. É uma teoria determinista porque para cada contexto, em concreto, existe uma configuração estrutural que melhor se lhe ajusta.

. É uma teoria funcionalista porque atribui à estrutura o papel de redesenhar os seus parâmetros para se adaptar aos factores de contexto.

. É uma teoria objectiva porque privilegia o recurso a explicações de base material e racional, como a idade, o tamanho, a tecnologia ou o ambiente, para justificar o comportamento organizacional.

Sendo tantas as contingências e tal o dinamismo dos factores conjunturais, com os quais a empresa tem que lidar, esta discussão dos tipos ideais parece cada vez mais despicienda e mais despida de pertinência. Ao contrário, a flexibilidade e a adaptabilidade das estruturas organizacionais são certamente temas mais oportunos e mais pertinentes, porque deles depende a sobrevivência das empresas num ambiente tão turbulento e tão incerto.

Paralelamente, não se pode ignorar o papel dos indivíduos e das suas estratégias pessoais na escolha de um desenho estrutural. O processo de mudança organizacional nunca pode ser isolado das acções e das preferências individuais, das opções de quem detém o poder, como sugeriu Child $(1972,1997)$. Trata-se de conciliar o pragmatismo dos pontos de vista contingentes com o relativismo implícito nas abordagens mais próximas da decisão dos actores (Crozier e Friedberg, 1986; Thiétart, 1997). Trata-se igualmente de não isolar o fenómeno organizacional das circunstâncias em que se produz, dando uma especial relevância aos aspectos sociais, políticos ou culturais em que está integrado. Apesar de isso limitar as suas possibilidades de generalização, e de pôr um ponto final no seu pretenso universalismo, a mudança organizacional só pode ser entendida no quadro geográfico e cultural em que se concretiza (Rosenzweig, 1994; Coelho, 2000). 


\section{O Estudo Proposto}

$\mathrm{Na}$ ausência de um referencial ou de estudos que avaliem os níveis de estruturação das empresas, o objectivo do trabalho que ora se apresenta é o de averiguar se se terão alcançado os níveis mínimos de organização administrativa e do trabalho produtivo, compatíveis com o novo cenário concorrencial em que as empresas ibéricas estão integradas. Podendo parecer um trabalho contra a corrente, num momento em que se fala de horizontalização e de virtualização das estruturas organizativas, começa a generalizar-se a suspeita de que a organização produtiva está ainda na fase de arranque, em particular no espaço que este trabalho visa estudar: a Península Ibérica. Nestes termos, ainda que não se deva ou possa falar de estrutura ou de estruturação ideal, poder-se-á, pelo menos, falar em níveis mínimos de estruturação que assegurem a fluidez dos processos, uma produtividade aceitável e uma capacidade competitiva efectiva.

A actualidade e a pertinência deste estudo advêm, no fundamental, da prevalência das dificuldades experimentadas pelas empresas ibéricas, com especial destaque para as portuguesas, em enfrentar uma concorrência aguerrida a operar numa lógica global. A produtividade e, consequentemente, a competitividade destas empresas mantêm-se em níveis particularmente problemáticos, que são visíveis nas situações mais inverosímeis: empresas espanholas, cujas unidades portuguesas encerram porque, apesar das enormes diferenças salariais, as unidades em Espanha são mais produtivas e rentáveis; empresas portuguesas, cujas filiais espanholas são igualmente mais produtivas e rentáveis, apesar dos incrementos salariais.

Quando as tecnologias, as matérias-primas e os produtos conhecem uma tão grande padronização, quando o conhecimento das técnicas se dissemina tão rapidamente, começam a reduzir-se significativamente os factores aos quais se poderão imputar responsabilidades por esta situação. As pessoas e os modelos organizativos das empresas são já dos poucos factores que resta explorar. Ainda assim, as pessoas, como trabalhadoras, deram já provas, em todo o mundo, das suas capacidades e da sua produtividade. Logo, a estruturação das empresas é um factor ao qual se deverá atribuir alguma prioridade, e que será objecto deste estudo.

De facto, um tecido empresarial constituído por unidades de muito pequena dimensão, com uma gestão familiar e autodidacta, apresenta os requisitos básicos para desencadear uma significativa inércia organizativa e para inibir a tendência estruturadora que se reconhece às organizações. Não é por isso difícil encontrar exemplos de empresas que necessitam parar algumas secções quando há camiões 
para carregar ou descarregar ou onde os operários se deslocam pelas distintas secções em função das necessidades pontuais, vivendo em regime de perfeita adaptação mútua.

Nestes termos, elegeu-se um conjunto de proposições relativamente às quais se pretende trazer alguma discussão e algum tipo de compreensão adicional. Fala-se aqui de proposições e não de hipóteses porque, apesar da natureza quantitativa do estudo e dos resultados, não se pretende aceitar ou rejeitar liminarmente nada, mas apenas, a partir dos indícios recolhidos, poder confirmar ou infirmar os pontos de vista propostos. Nestes termos, a primeira proposição é a que passamos a apresentar.

\section{Proposição I}

Os factores demográficos influenciam decisivamente o nível de estruturação das empresas.

As características específicas do tecido empresarial ibérico, nomeadamente as já referidas dimensão reduzida e gestão familiar autodidacta, poderão ser susceptíveis de inibir a vontade estruturante da empresa. Estes efeitos deverão ser mais visíveis entre as empresas portuguesas, onde também estas características deverão apresentar maior prevalência.

\section{Proposição II}

Por força dos factores de contexto, e independentemente da direcção e intensidade dos seus movimentos, as empresas evoluem sempre no sentido de maior estruturação.

O tema de partida para este trabalho parte da convicção de que as empresas ibéricas se encontram subestruturadas. Subestruturação quer aqui dizer que não foram alcançados os níveis mínimos de estruturação, isto é, de intensidade administrativa e de racionalização do trabalho produtivo, compatíveis com a dimensão da empresa.

A confirmar-se uma efectiva subestruturação das empresas, qualquer estímulo acabará por produzir efeitos de natureza estruturante, pelo menos até que se alcancem os níveis mínimos de estruturação, susceptíveis de optimizar a produtividade. Analogamente, a produzirem-se estes efeitos, em particular num cenário tão instável e tão incerto como o que se vive na actualidade, começa a ganhar conteúdo a proposta inicial, da hipotética subestruturação das empresas. Convém não esquecer que, de acordo com a teoria dominante, um ambiente instável exige estruturas preferencialmente orgânicas (Mintzberg, 1979; Fuente 
Sabaté, 1994), a menos que circunstâncias específicas possam justificar o contrário (Coelho, 2000).

\section{Proposição III}

As mudanças de carácter disruptivo têm um carácter deliberado e potenciam a mudança na estruturação das organizações.

As estruturas não são tão adaptativas nem apresentam comportamento tão mimético quanto os pontos de vista positivistas poderiam deixar antever (Coelho e Almeida, 2000). Os movimentos de adaptação estrutural aos factores de contexto não apresentam um carácter meramente passivo; pelo contrário, expressam as preferências e as opções de todos aqueles que detêm o poder no seio das organizações (Child, 1997; Thiétart, 1997). A existência de mudanças de natureza disruptiva, fora da gestão corrente, só poderá ser justificada pelo exercício de opções e preferências relativas ao modelo organizativo da empresa. Nestes termos, a opção por mais estruturação, num cenário que aconselha estruturas preferencialmente ligeiras e ágeis, só poderá ser entendida no quadro de uma subestruturação latente.

\section{Metodologia}

Os resultados alcançados, relativamente ao conjunto de proposições apresentadas, foram obtidos a partir de um inquérito a que se procedeu com 187 empresas, das quais 96 são portuguesas e 91 são espanholas, da região da Catalunha. Trata-se de um conjunto de empresas com mais de 20 trabalhadores, eleitas aleatoriamente, a partir dos ficheiros do Instituto do Comércio Exterior de Portugal, que inclui as empresas portuguesas com operações em Espanha, assim como as empresas espanholas com operações em Portugal. Estas empresas pertencem a um universo de 1.826 registos constantes destes ficheiros, dos quais se extraiu uma amostra de 200, das quais 187 aceitaram participar deste estudo.

Tratou-se assim de reunir um conjunto de empresas a operar num mercado com características comuns e, em principio, sujeitas a um conjunto de pressões de características igualmente comuns. $\mathrm{O}$ estudo tinha como objectivo básico a identificação dos comportamentos e das práticas organizacionais das referidas empresas e permitiu a recolha de informações pertinentes relativas à problemática que aqui se pretende discutir.

A recolha de informações fez-se utilizando o método da entrevista, apoiada num questionário semidirectivo, dirigido ao director geral da empresa ou a um 
director de primeira linha. O referido questionário foi estruturado à volta de dois grandes conjuntos de variáveis: o primeiro ligado às percepções sobre a evolução do ambiente externo; o segundo às mudanças nos parâmetros estruturais da empresa. Em paralelo, procurou-se identificar o perfil demográfico das empresas, assim como o seu comportamento estratégico.

As variáveis relativas ao ambiente externo que foram utilizadas privilegiam, exclusivamente, as percepções dos dirigentes sobre a sua evolução, uma vez que são estas percepções que vão permitir desencadear as acções de resposta (Ford e Slocum, 1977; Oswald, 1997). A incerteza quanto à evolução das variáveis ambientais tem conhecido diversas abordagens: a intensidade e a imprevisibilidade das mudanças foi uma das primeiras versões, apresentada por Emery e Trist (1961); a disponibilidade de informação foi proposta por Duncan (1972) e por Milliken (1987); Pfeffer e Salancik (1978) falam da disponibilidade de recursos e da dependência que ela supõe para a organização. A perspectiva que aqui se vai adoptar encontra as suas raízes nos trabalhos de Child (1972) e de Mintzberg (1979), mais tarde operacionalizada por Kalika (1988) e por Coelho (1990), e utiliza a complexidade, a variabilidade e a hostilidade como as variáveis base. A complexidade é consequência do número de factores e variáveis relevantes e do número de actividades desenvolvidas pela empresa. A variabilidade recolhe a importância, a intensidade e a frequência das mudanças em curso. A hostilidade mede o risco que estas mudanças supõem para a sobrevivência da empresa.

A estrutura organizativa da empresa tem merecido uma conceptualização mais uniforme. Os parâmetros retidos estão próximos dos utilizados por Kalika (1988) e por Coelho (1990), e englobam a padronização de tarefas, a formalização de informações e comunicações, os mecanismos de planificação e controle, os níveis de centralização/descentralização e a forma estrutural que recolhe a hierarquia da empresa.

Foi adoptada uma perspectiva multidimensional na avaliação de cada uma destas variáveis, que foram medidas a partir da utilização de entre 3 e 7 dimensões. A coerência destas escalas foi avaliada utilizando o Alfa de Chronbach, tendo todas elas recolhido valores superiores a 0,8 .

Para avaliar a fiabilidade das medidas, a partir da sua consistência ao longo do tempo, utilizou-se o test retest, repetindo a aplicação do questionário num grupo de 15 empresas, com um mês de intervalo. Não se encontraram diferenças significativas $(p>0,05)$ entre as respostas obtidas, utilizando o $\mathbf{t}$ de Student e o teste de Wilcoxon.

A principal limitação dos resultados dos estudos transversais, que não recolhem 
mais que uma fotografia da organização, é que desprezam o acompanhamento do processo e apresentam uma relação causa/efeito, normalmente mais que duvidosa. Por isto, e uma vez que este é também um estudo transversal, procurouse identificar mais o processo de mudança, que a situação em si. Isto é, os entrevistados não foram questionados sobre o número de regras e procedimentos, ou sobre a intensidade da concorrência, mas sobre a evolução que estes parâmetros vinham a conhecer. Esta opção permitiu ter em conta os caminhos que as empresas estão a seguir e, simultaneamente, deu uma base de comparação aos entrevistados, o que permite homogeneizar mais as suas respostas.

Pretendeu-se, finalmente, criar uma medida compósita que, combinando o número de níveis hierárquicos com o número de departamentos e com o tamanho da empresa, permitisse a avaliação e o poder ter uma medida de comparação do estádio estrutural das diversas empresas da amostra.

Avaliar o nível de estruturação das empresas é particularmente complexo, quando não se dispõe de uma metodologia sólida e testada, ou de valores de referência. Ainda assim, o facto de se poder dispor de dados relativos a empresas espanholas e portuguesas, vai desde logo tornar possível uma base de comparação.

\section{Os Resultados}

\section{Os Factores Demográficos}

Os resultados obtidos mostraram, de imediato, a existência de um conjunto significativo de empresas cuja forma estrutural não se enquadrava em nenhuma das categorias normalmente tipificadas. De imediato se procedeu à operacionalização de um tipo de estruturas, já referidas por Kalika (1988) e catalogadas por Coelho $(1990,2000)$ como empresarial-nascentes. Este tipo de estruturas caracteriza-se pela incipiência da sua estruturação e obedece a uma dupla perspectiva:

. Elas são empresariais porque o dono da empresa desempenha um papel omnipresente e omnisciente na gestão da empresa, funcionando como um verdadeiro homem-orquestra.

. Elas são nascentes porque ainda não se pode falar de uma verdadeira estrutura organizativa. O organigrama não se encontra formalizado, as funções estão mal definidas, não existem quadros de direcção, prevalece a polivalência e a coordenação faz-se por ajuste mútuo. 
Em suma, trata-se de empresas com uma forma estrutural mal definida, onde não se encontram mais que vestígios de padronização de tarefas e nenhuma formalização, o planeamento está ausente e o controle e a decisão permanecem concentrados no patrão. Elas podem ser vistas como embrionárias das formas funcionais, ou como formas pré-funcionais (Kalika, 1988).

No presente estudo, foram consideradas como empresarial-nascentes todas as empresas que não tinham pelo menos um departamento com cargo de direcção e que, entre o lugar de gerente e a base da hierarquia, não tinham mais que um nível de chefias intermédias, sendo a direcção assegurada pelo dono.

Os resultados obtidos são os que passamos a apresentar.

\begin{tabular}{|l|c|c|}
\hline & Empresas Portuguesas & Empresas Catalãs \\
\hline Vol. de Neg./no de empregados & 60404 & 127008 \\
\hline Empresarial-nascentes & 37 & 14 \\
\hline Funcionais & 59 & 76 \\
\hline Outras & 0 & 1 \\
\hline Com organigrama & 63 & 59 \\
\hline Sem organigrama & 33 & 32 \\
\hline Estruturação & 5.95 & 9.97 \\
\hline Estruturação ponderada & 2.83 & 4.65 \\
\hline Gestão familiar & 72 & 43 \\
\hline Gestão familiar assistida & 14 & 24 \\
\hline Gestão profissional & 10 & 24 \\
\hline D.G. autodidacta & 16 & 0 \\
\hline D.G. c/ formação média & 38 & 10 \\
\hline D.G. c/ formação superior & 42 & 81 \\
\hline Sociedades de resp. limitada & 54 & 2 \\
\hline Sociedades anónimas & 42 & 88 \\
\hline
\end{tabular}

Os dados relativos à estruturação coincidem com os valores obtidos para a variável compósita, criada a partir do cruzamento do número de níveis hierárquicos com o número de departamentos. Todavia, atendendo ao facto do tamanho da estrutura tender a crescer com a dimensão da empresa, procedeu-se à sua ponderação com o logaritmo do número de empregados. A utilização do logaritmo prende-se com uma recomendação de Kimberly (1976), ratificada por outros autores, pelo facto de o processo administrativo ser mais sensível às variações de dimensão nas empresas de pequena dimensão. Graças às sinergias e às economias de escala, a estrutura tende a crescer menos que proporcionalmente à dimensão da empresa.

Testados estes valores utilizando o Qui quadrado, detectaram-se diferenças de comportamento significativas $(\mathrm{p}<0,05)$ entre empresas catalãs e portuguesas para o tamanho, para a forma estrutural, para a estruturação, para o tipo de direcção e formação do director geral, assim como para o tipo societário. Estes dados coincidem com os resultados de uma análise discriminante que permitiu traçar o perfil das empresas estudadas. Assim: 
- A empresa portuguesa é uma sociedade de responsabilidade limitada, pouco estruturada, dirigida por um empresário autodidacta.

- A empresa espanhola é uma sociedade anónima, com uma estrutura bastante mais definida, dirigida por um profissional ou pelo empresário apoiado nos seus directores, com uma formação média ou superior.

Como seria de esperar, adoptando idênticos procedimentos relativamente às variáveis de estruturação, verificou-se existirem diferenças significativas $(p<0,05)$ para os diferentes parâmetros demográficos, confirmando o que já parecia evidente: as empresas de pequena dimensão, geridas pelo empresário com formação autodidacta, que têm a forma de sociedades de responsabilidade limitada, são as que apresentam menor estruturação.

Naturalmente, seria de esperar que à medida que a dimensão da empresa vai aumentando, a estruturação relativa (ponderada) fosse diminuindo, pelas razões já apresentadas. Ainda assim, o que se verificou é que à medida que a dimensão aumentava, aumentava igualmente a estruturação relativa. A partir de uma regressão linear em que a estruturação surgia como variável dependente do logaritmo do tamanho, pode constatar-se esta relação positiva entre as duas:

Estruturação $=-0,741+2.164 \log$. do tamanho $+E ; R^{2}=0,125:(p<0.05)$

Estes resultados mostram que, de alguma maneira, a vontade de organizar se desenvolve com o tamanho e que, ou as empresas de maior dimensão são excessivamente burocráticas, ou as de menor dimensão estão claramente subestruturadas. De qualquer forma, a primeira proposição, segundo a qual a estruturação é condicionada pelos factores demográficos, parece estar aqui amplamente corroborada.

\section{A Mudança Estrutural}

Outra das vertentes deste estudo prende-se com o comportamento das organizações, no que respeita à mudança estrutural. Esta vertente ganha uma particular acuidade se se tem em conta a conjuntura vivida nestes dois países que, depois da adesão às comunidades e ao mercado único europeu, viram as suas empresas submergir num turbilhão de mudanças, que ameaça continuar e aprofundar-se.

Nestes termos, seria de esperar que as empresas destes dois países, se se cumprissem as profecias, começassem um processo de aligeiramento das suas estruturas organizativas, dando-lhes um funcionamento mais orgânico. Curiosamente, o movimento desencadeado teve exactamente a direcção inversa. Convém contudo notar que, antes de mais, o dado mais relevante aponta para a 
inércia estrutural destas empresas, que parecem ignorar os acontecimentos no exterior e mantêm as suas estruturas praticamente inalteradas (Coelho e Almeida, 2000). De facto, as mudanças registadas nos parâmetros destas empresas são muito ligeiras e escondem uma realidade de uma ampla maioria que se mantém relativamente inerte (nível I), em face de um pequeno grupo que, de facto, introduz mudanças substanciais nas suas estruturas (nível III), como consta do quadro que de seguida se reproduz.

\begin{tabular}{|l|c|c|c|}
\hline & Nivel I & Nivel II & Nivel III \\
\hline Forma Estrutural & 149 & 38 & - \\
\hline Padronização & 66 & 98 & 23 \\
\hline Formalização & 74 & 63 & 50 \\
\hline Planeamento e Controle & 103 & 79 & 5 \\
\hline Centralização / Descentr. & 153 & 34 & - \\
\hline
\end{tabular}

O dado mais significativo é que todas as mudanças foram na mesma direcção e foram no sentido de uma estruturação mais desenvolvida, com especial destaque para a padronização, para a formalização, e para o planeamento e controle. Curiosamente, a padronização de tarefas é o parâmetro que os entrevistados mais associam ao conceito de organização.

Depois de se haver constatado que todos os movimentos de adaptação foram no sentido do reforço dos parâmetros estruturais, pôde igualmente constatar-se que as empresas que mais sentem o dinamismo do ambiente são aquelas que mais mudam as suas estruturas. Esta mudança é no sentido de maior estruturação, como reflecte o resultado do modelo que de seguida se apresenta, que mostra que a intensidade das mudanças organizacionais depende da percepção quanto à intensidade das mudanças ocorridas no exterior da empresa:

Mudanças estruturais $=0.467+0,947$ mudanças no ambiente $+E ;(p<0.05)$; $\mathrm{R}^{2}=0.351$

Curiosamente, acabamos por constatar que as empresas estão a enfrentar um maior dinamismo no ambiente dos seus negócios, traduzido em maior complexidade, em maior variabilidade e em maior hostilidade, com o reforço da sua estrutura organizativa. Os dados que seguidamente se reproduzem, dão conta deste movimento.

\begin{tabular}{|l|c|c|c|c|}
\hline & Complexidade & Variabilidade & Hostilidade & Ambiente Global \\
\hline Padronização & $0.40(\mathrm{p}<0.05)$ & $0.34(\mathrm{p}<0.05)$ & $0.10(\mathrm{p}>0.05)$ & $0.40(\mathrm{p}<0.05)$ \\
\hline Forma Estrutural & $0.49(\mathrm{p}<0.05)$ & $0.51(\mathrm{p}<0.05)$ & $0.05(\mathrm{p}>0.05)$ & $0.54(\mathrm{p}<0.05)$ \\
\hline Formalização & $0.47(\mathrm{p}<0.05)$ & $0.43(\mathrm{p}<0.05)$ & $0.10(\mathrm{p}>0.05)$ & $0.49(\mathrm{p}<0.05)$ \\
\hline Descentralização & $0.13(\mathrm{p}>0.05)$ & $0.20(\mathrm{p}<0.05)$ & $0.06(\mathrm{p}>0.05)$ & $0.17(\mathrm{p}<0.05)$ \\
\hline Planeamento e controle & $0.49(\mathrm{p}<0.05)$ & $0.53(\mathrm{p}<0.05)$ & $0.22(\mathrm{p}<0.05)$ & $0.56(\mathrm{p}<0.05)$ \\
\hline Planificação & $0.35(\mathrm{p}<0.05)$ & $0.46(\mathrm{p}<0.05)$ & $0.24(\mathrm{p}<0.05)$ & $0.46(\mathrm{p}<0.05)$ \\
\hline Controle & $0.50(\mathrm{p}<0.05)$ & $0.46(\mathrm{p}<0.05)$ & $0.13(\mathrm{p}<0.05)$ & $0.52(\mathrm{p}<0.05)$ \\
\hline Estrutura Global & $0.54(\mathrm{p}<0.05)$ & $0.55(\mathrm{p}<0.05)$ & $0.13(\mathrm{p}<0.05)$ & $0.59(\mathrm{p}<0.05)$ \\
\hline
\end{tabular}


As correlações apresentadas entre as variáveis ambientais e os parâmetros estruturais parecem mostrar que, em face da incerteza, maior estruturação parece dar maior sensação de controle sobre os acontecimentos. Assim, a um ambiente dinâmico deixa de corresponder uma estrutura orgânica e passa a corresponder uma estrutura, aparentemente, mais mecânica, com uma estruturação mais desenvolvida. A única explicação que ocorre é a de que, mais uma vez, perante uma situação de hipotética subestruturação, as empresas estão à procura da consolidação das suas estruturas.

Naturalmente, esta é uma situação que vem ao arrepio de tudo o que se poderia esperar e, dessa maneira, corrobora as afirmações contidas na segunda proposição, segundo a qual, independentemente dos factores de contexto, as estruturas evoluem no sentido do seu reforço.

\section{O Papel da Decisão}

Os movimentos de adaptação das estruturas organizativas das empresas aos factores de contexto não acontecem, como já foi referido, de forma mimética e passiva. As mudanças concretizadas inscrevem-se num quadro de preferências e opções, cristalizadas nas decisões operadas. Há mesmo um debate interessante que põe em contraponto as mudanças incrementais versus as mudanças disruptivas. Um dos alertas importantes que resulta deste debate tem que ver com as resistências internas à mudança, com a inércia que se instala e que nem sempre é possível vencer, excepto se por força de um acontecimento maior, uma opção clara, que rompa os esquemas e permita mudança global, em todas as frentes.

Nestes termos procurou-se, em primeiro lugar, cruzar a informação relativa às mudanças em curso nas opções estratégicas da empresa com as mudanças estruturais concretizadas. Os resultados alcançados encontram-se resumidos no quadro que de seguida se apresenta.

\begin{tabular}{|l|c|c|c|c|}
\hline & $\begin{array}{c}\text { Estratégia } \\
\text { Estável }\end{array}$ & $\begin{array}{c}\text { Estratégia em } \\
\text { Mudança }\end{array}$ & Média & $\begin{array}{c}\text { Correlações de } \\
\text { Pearson }\end{array}$ \\
\hline Padronização & 4,80 & 5,25 & 5,01 & $0,36(\mathrm{p}<0.05)$ \\
\hline Forma Estrutural & 4,27 & 4,73 & 4,48 & $0,52(\mathrm{p}<0.05)$ \\
\hline Formalização & 4,64 & 5,36 & 4,97 & $0,44(\mathrm{p}<0.05)$ \\
\hline Descentralização & 4,15 & 4,43 & 4,28 & $0,36(\mathrm{p}<0.05)$ \\
\hline Plan./controle & 4,60 & 5,11 & 4,84 & $0,47(\mathrm{p}<0.05)$ \\
\hline Planeamento & 4,33 & 4,81 & 4,56 & $0,42(\mathrm{p}<0.05)$ \\
\hline Controle & 4,96 & 5,50 & 5,21 & $0,40(\mathrm{p}<0.05)$ \\
\hline Global & 4,49 & 4,97 & 4,71 & $0,53(\mathrm{p}<0.05)$ \\
\hline
\end{tabular}

As mudanças operadas nas estratégias das empresas parecem, de facto, ter tido um impacto significativo nos ajustamentos estruturais verificados. A correlação 
existente entre as variáveis estratégicas e as variáveis estruturais é confirmada pelo $\mathbf{t}$ de Student, que mostra existirem diferenças significativas $(\mathrm{p}<0,05)$ entre os dois grupos de empresas.

Paralelamente, as empresas que apresentaram mudanças de carácter disruptivo apresentam, igualmente, alterações de fundo no seu funcionamento, que motivaram esta ruptura. No caso desta amostra de empresas, a certificação da qualidade foi o factor que permitiu desencadear este processo de mudança e reconduzir a sua configuração estrutural. Os dados que permitiram chegar a estas conclusões, estão expressos no quadro que a seguir se apresenta.

\begin{tabular}{|l|c|c|c|}
\hline & Mudanças Progressivas & Mudanças Disruptivas & Total \\
\hline Sem Certificação & 84 & 4 & 88 \\
\hline Com Certificação & 17 & 82 & 99 \\
\hline Total & 101 & 86 & 187 \\
\hline
\end{tabular}

Utilizando o Qui Quadrado verifica-se que são significativamente $(\mathrm{p}<0,05)$ distintos os comportamentos de ambos os grupos de empresas. A natureza das mudanças operadas depende, significativamente, da existência de um estímulo forte, como a certificação da qualidade, que obriga a repensar toda a organização e a sua estrutura, e conduz a uma acção generalizada sobre toda a empresa.

Assim, pode concluir-se que, por detrás dos movimentos de ajustamento das estruturas organizativas das empresas aos seus factores de contexto, existe uma linha de acção que expressa as vontades, os objectivos e as preferências da direcção da empresa. Isto é, a terceira proposição apresentada parece também ser corroborada pelos factos: apesar de nem só as mudanças disruptivas terem este carácter deliberado, é provavelmente nelas que ele é mais evidente, e dele resulta uma mudança estrutural mais efectiva.

\section{Discussão dos Resultados}

Os resultados alcançados, e aqui divulgados, apresentam um alcance que transcende os objectivos e os propósitos deste trabalho. Todavia estes serão os guias da discussão a encetar. Do nosso ponto de vista, a corroboração das três proposições apresentadas permite, na ausência de estudos, metodologias ou valores de referência credíveis, dar algum conteúdo e validade ao título deste trabalho.

Falar da existência de um déficit estrutural ou de uma subestruturação latente nas empresas ibéricas, e em particular nas portuguesas, é uma afirmação, antes 
de mais, altamente discutível, que encerra até mesmo algum risco. Todavia todos os indícios recolhidos parecem encaminhar-se nesse sentido.

A primeira proposição, ao fazer depender o desenvolvimento estrutural das organizações dos factores demográficos que as caracterizam, está desde logo a alertar para a existência de uma constelação de elementos, com particular visibilidade na realidade portuguesa, que são inibidores do desenvolvimento de uma mentalidade organizadora. A presença dos empresários na gestão das empresas, independentemente de todos os inegáveis méritos da sua contribuição, fará com que sempre se dê prioridade à manutenção do seu poder e dos seus mecanismos de controle. Eis pois um forte conjunto de incentivos à inércia e à subestruturação.

A segunda proposição prevê um movimento uniforme no sentido de uma estruturação mais consolidada, independentemente do sentido da evolução dos factores de contexto. De facto, o movimento registado é fortemente contraditório com as expectativas mais amplamente criadas pela aceleração do dinamismo registado no ambiente dos negócios das empresas: supostamente, um ambiente dinâmico faz-se acompanhar de uma estruturação orgânica. Todavia as estruturas parem ter ganho um carácter preferencialmente mecânico. Nestes termos, o reforço e consolidação das organizações a que se assistiu só é compreensível no quadro de uma insuficiência estrutural, que agora começa a ser colmatada.

Finalmente, o carácter deliberado e até estratégico das mudanças operadas não poderá deixar de confirmar a ideia com que se partiu para este trabalho, em duas vertentes distintas: a primeira, que resulta da assunção de que a estruturação das empresas é incipiente; a segunda, que coincide com a decisão de, independentemente de tudo, proceder ao reforço dos parâmetros estruturais das empresas. Não deixa, igualmente, de ser curioso que numa época em que se fala de desburocratização, que se repudia a hierarquia, que se propõe a virtualização das organizações e mesmo das suas estruturas, se assista a um movimento de características tão tayloristas e tão contra a corrente, que parece descobrir agora as virtualidades da divisão do trabalho. Ainda assim, autores como Perrow (1986) defendem que princípios de natureza tão pragmática como estes não correm o risco de obsolescência. "Os princípios funcionaram e continuam a funcionar na actualidade, porque se orientam para a resolução de problemas muito concretos de administração, problemas mais urgentes para os gestores que aqueles que são analisados pela ciência social" (Perrow, 1986).

Apesar de todas as limitações e de todas as dificuldades, a existência de uma insuficiência estrutural nestas empresas é uma possibilidade a ter em conta e que 
sai, aparentemente, reforçada com o conjunto de indícios que foi possível apresentar. Esta possibilidade deve ser objecto de uma reflexão profunda em diversos níveis:

. No nível da investigação no âmbito organizacional, já que os resultados dos estudos realizados não devem nem podem dissociar-se da realidade em que se produzem. Analogamente, os resultados produzidos podem, por vezes, apresentar este carácter inesperado, sobretudo quando se está em presença de uma constelação de forças tão significativa, como a vivida pelas empresas ibéricas.

- No nível da gestão destas mesmas empresas, cuja competitividade pode ser claramente reforçada com um conjunto de medidas e acções, cujos resultados podem ter menor visibilidade e menor imediatez, mas que dão uma contribuição decisiva para o reforço das sinergias internas e para maior capacidade de resposta às mudanças em curso no ambiente dos seus negócios.

. No nível da política industrial, onde muitos dos apoios, muitos dos incentivos, muitas das prioridades resultam esvaziadas de sentido, se não integrarem uma necessária reestruturação, que torne coerentes e potencie os efeitos das medidas e dos investimentos realizados.

\section{Conclusão}

Falar da debilidade estrutural das organizações, quando a tendência geral parece apontar em sentido contrário, num momento em que se fala de horizontalização e de achatamento das hierarquias, de estruturas em rede e de estruturas virtuais, pode parecer fora de tempo. Ainda assim, os problemas específicos das empresas ibéricas, entre as quais se destacam as portuguesas, com níveis de produtividade muito baixos e com uma competitividade mais que limitada, fazem com que este problema mereça ser claramente equacionado.

Na ausência de medidas, metodologias ou padrões já amplamente testados, foi possível reunir um conjunto de indícios que apontam, com alguma insistência, no sentido da prevalência de uma significativa subestruturação nestas empresas. A prevalência generalizada de empresas com estruturas caracterizadas como empresarial-nascentes, a sua reduzida dimensão, a presença do empresário autodidacta na sua gestão, criam um quadro específico que levanta problemas de capacidade de gestão e de vontade organizadora.

A importância que estes factores, de natureza demográfica, parecem ter na estruturação das empresas e a sua ampla presença, em particular entre as 
empresas portuguesas, dão já alguma razão de ser à problemática proposta. Se a isto juntarmos a tendência estruturadora com que, ao arrepio das teses normalmente defendidas, a generalidade das empresas pretendem responder a um ambiente que se apresenta mais complexo, mais variável e mais hostil, o problema ganha conteúdo e pertinência. Se finalmente tivermos em conta que este movimento parece obedecer a um conjunto de propósitos, preferências ou opções da direcção das empresas, no sentido de reforçar os seus parâmetros estruturais, parece então que poderemos falar de um sério problema de subestruturação.

Ainda que este movimento de características tayloristas possa parecer algo obsoleto, convém recordar as razões pelas quais Drucker (1999) sugere que a hierarquia nunca morrerá: "quando o navio se afunda não faz falta marcar reuniões, há que dar ordens e assumir responsabilidades".

Este conjunto específico de problemas enfrentados por estas empresas, deve alertar os investigadores para as possibilidades de generalização dos seus resultados, assim como para o importante comprometimento que, muitas vezes, existe entre estes e a realidade em que foram produzidos. Deve igualmente resultar a consciência para a direcção das empresas e para os responsáveis pela política industrial, de que a estruturação é uma prioridade básica, susceptível de permitir a optimização da utilização dos recursos das empresas.

\section{Referéncias Bibliográficas}

ANASTASSOPOULOS, J. P. et al.

Pour une nouvelle politique d'entreprise. Paris: PUF, 1985.

BURNS, T.;

STALKER, G. M.

The management of innovation. London: Tavistock Publications, 1961.

CHANDLER, A.

Strategy and structure. Boston: MIT Press, 1962.
CHILD, J.

Organizational structure, environment and performance: the role of strategic choice. Sociology, v. 6, p. 1-22, 1972a.

Organization structure and strategies of control: a replication of the Aston study. Administrative Science Quarterly, n. 17, p. 163-177, 1972b. 
Predicting and understanding organization structure. Administrative Science Quarterly, v.3, n. 18, p. 168-185, 1973.

Information technology, organization, and the response to S. California Management Review, v. 30, n. 1, p. 33-51, 1987.

\section{Management in China during the age of Reform. Cambridge: Cambridge University Press, 1994.}

Strategic choice in the analysis of action, structure, organizations and environment: retrospect and prospect. Organization Studies, v. 18, n. 1, p. 43-76, 1997.

CHILD, J.;

SMITH, C.

The context and process of organizational transformation Cadbury Limited. Journal of Management Studies, v. 24, n. 6, p. 265-584, 1987.

COELHO, A.

Environment et structures: une relation contingent? Poitiers: Institut d'Administration d'Entreprises, 1990.
A dinâmica estrutural das organizações. [S.1.]: Instituto de Ciencias de la Educación de la Universidad de Málaga, 1997.

El management en un entorno dinámico: la certificación de la calidad como factor estructurante - un estudio comparativo entre empresas portuguesas y catalanas. Barcelona, 2000. Tesis (Doctoramiento) - Universidad de Barcelona.

COELHO, A.; ALMEIDA, F.

De un marketing transaccional a un marketing contractual. In: JORNADAS HISPANO-LUSAS DE GESTÃO CIENTÍFICA, IX., 1999, [S.1.]. Actas... [S.1.: s.n.], 1999.

A inércia estrutural das organizações e o papel estruturante da certificação da qualidade: o exemplo ibérico. In: ENCONTRO ANUAL DA ANPAD, XIV, 2000, Florianópolis. Anais... Florianópolis: ANPAD, 2000. 1 CD-ROM.

CROZIER, M.;

FRIEDBERG, E.

L'acteur et le système. Paris : Éditions du Seuil, 1977.

DONALDSON, L.

For positivist organization theory. London: Sage Publications, 1996.

A positivist alternative to the structure-action approach. Organization Studies, v. 18, n. 1, p. 77-92, 1997. 
DRUCKER, P.

Management challenges for de $2^{\text {st }}$ century. [S.1.]: Harper Collins, 1999.

\section{DRUCKER FOUNDATION.}

The organization for the future.

New York: Jossey-Bass, 1997.

DUNCAN, R. B.

Characteristics of organizational environments and perceived environmental uncertainty. Administrative Science Quarterly, n. 17, p. 313-327, 1972.

EMERY, F. E.;

TRIST, E. L.

The causal texture of organizational environments. Human Relations, v. 18, p. 2132, 1965.

FORD, J. D.;

SLOCUM JR., J. W.

Size, technology, environment and the structure of organizations. Academy of Management Review, n. 2, p. 561-575, 1977.

FREEMAN, J.

Efficiency and rationality in organizations. Administrative Science Quarterly, v. 44, n. 1, p. 163-175, 1999.

FUENTE SABATÉ, J. M.

Estructura organizativa y eficiencia empresarial: propuesta de un modelo contingente de análisis. Economía Z, n. 30, p. 178-197, 1994.
GALÁN ZAZO, J. I.

Análisis económico de los problemas del límite y la forma eficiente de organización. Información Comercial Española, n. 757, p. 134-154, 1996.

HANNAN, M. T.;

FREEMAN, J.

The population ecology of organizations. American Journal of Sociology, v. 82, n. 5, p. 929964, 1977.

Structural inertia and organizational change. American Sociological Review, v. 49, p. 149-164, 1984.

Organizational ecology. Cambridge: Harvard University Press, 1989.

HOUSE, R. J.;

SHANE, S. A.;

HEROLD, D. M.

Rumours of the death of dispositional research are vastly exaggerated. Academy of Management Review, v. 21, n. 1, p. 203-215, 1996.

INTERNATIONAL STANDARDS ORGANIZATION.

ISO9000 for small business: what to do - advice from ISO. Paris, ISO, 1996. 
JENNINGS, D. F.;

SEAMAN, S. L.

High and low levels of organizational adaptation: an empirical analysis of strategy, structure, and performance. Strategic Management Journal, v. 15, p. 459-475, 1994.

KALIKA, M.

Structure organisationnelle et technologie. [S.1.], Institut de Gestion de Touraine-Tours, 1987.

Structures d'entreprise: réalités, determinants, performance. Economica, 1988.

De l'organisation réactive à la organisation anticipative. Révue Française de Géstion, p. 46-51, nov./déc. 1991.

KNIGHTS, D.

Organization theory in the age of deconstruction: dualism, gender, and postmodernism revisited. Organization Studies, v. 18, n. 1, p. 1-19, 1997.

LACHMAN, R.;

NEDD, A.;

HININGS, B.

Analysing cross-national management and organizations: a theoretical framework.

Management Science, v. 40, n. 1, p. 40-55, 1994.
LAWRENCE, P. R.;

LORSCH, J. W.

Organization and environment.

Cambridge: Harvard University

Press, 1967.

LEBLEBICI, H.

New directions for organization theory: problems and prospects. The Academy of Management Review, v. 24, n. 1, p. 154-156, 1999.

LOUADI, M.

The relationship among organizational structure: information technology and information processing in small Canadian firms. Canadian Journal of Administrative Sciences, v. 15, n. 2, p. 180-199, 1998.

MILES, R. E.;

SNOW, C. C.;

PFEFFER, J.

Organizations and environment: concepts and issues. Industrial Relations, v. 13, p. 244-264, 1974.

MILLIKEN, F. J.

Three types of perceived uncertainty about the environment: state, effect, and response uncertainty. Academy of Management Review, v. 12, n. 1, p. 133-143, 1987.

MINTZBERG, $\mathrm{H}$.

The structuring of organizations.

Englewood Cliffs, NJ: Prentice-Hall, 1979. 
Meanings on management. Harvard Business Review, July 1996.

MONITOR COMPANY.

Construir as vantagens competitivas de Portugal. Lisboa, Cedintec, 1994.

OSWALD, S. L.;

KEVIN, W. M.;

STANLEY, G. H.

Relations between strategic involvement and managers perceptions of environment and competitive strengths. Group \& Organization Management, v. 22, n. 2, p. 343-365, 1997.

PFEFFER, J.

New directions for organization theory: problems and prospects. New York: Oxford University Press, 1997.

PFEFFER, J.;

SALANCIK, G. R.

The external control of organizations: a resource dependence perspective. New York: Harper and Row, 1978.

PORTER, M.

What is strategy? Harvard Business Review, v. 74, n. 6, p. 61-80, 1996.

PRICE WATERHOUSE.

Europa y la competitividad de la economía Española. Barcelona, Ariel Economía, 1992.
PUGH, D. S. et al.

The context of organization structures. Administrative Science Quarterly, n. 14, p. 91114, 1969.

PUGH, D. S.;

HICKSON, D. J.;

HININGS, C. R.

An empirical taxonomy of structures of work organizations. Administrative Science Quarterly, n. 14, p. 115-126, 1969.

ROSENZWEIG, P. M.

When can management science research be generalized internationally? Management Science, v. 40, n. 1, p. 28-39, 1994.

SHENKAR, O.;

VON GLINOW, M. A.

Paradoxes of organizational theory and research: using the case of China to illustrate national contingency. Management Science, v. 40, n. 1, p. 56-71, 1994.

SIMÕES, V. C.

Inovação e gestão em PME portuguesas. Lisboa: GEP, 1996.

THIÉTART, R. A.;

FORGUES, B.

Chaos, theory and organization. Organization Science, n. 6, p. 19-31, 1995.

Action, structure and chaos. Organization Studies, v. 18, n. 1, p. 119-141, 1997. 
URWICK, L. F.

Organization as a technical problem. New York: Gulick and Urwick, 1937. p. 49-88.
WEICK, K.

An appreciation of social context: one legacy of Gerald Salancik. Administrative Science Quarterly, v. 41, n. 4, p. 563-573, 1996. 